\title{
Utilization of Galactomannan from Gleditsia triacanthos in Polysaccharide-Based Films: Effects of Interactions Between Film Constituents on Film Properties
}

\author{
Miguel A. Cerqueira • Bartolomeu W. S. Souza • \\ José A. Teixeira • António A. Vicente
}

Received: 16 April 2011 /Accepted: 28 November 2011 /Published online: 17 December 2011

(C) Springer Science+Business Media, LLC 2011

\begin{abstract}
The objective of this work was to evaluate the effect of the concentrations of Gleditsia triacanthos galactomannan and glycerol and the presence of corn oil in the physical properties of edible films. The influence of interactions between those constituents on films' permeability to gases (water vapour, $\mathrm{CO}_{2}$ and $\mathrm{O}_{2}$ ), solubility in water, mechanical properties and colour was evaluated. The effects of those variables were analysed according to a $2^{3}$ factorial design; regression coefficients were used to understand the influence of each variable (factor) on the studied properties, and a multifactor model was developed. Results show that galactomannan concentration is the most significant factor affecting the studied properties; moreover, the increase of plasticizer concentration and the presence of oil showed to be the most influent in the particular cases of solubility and transport properties (water vapour permeability and $\mathrm{O}_{2}$ permeability), respectively. These results show that galactomannan films' properties can be tailored to allow their use as alternative to non-biodegradable, non-edible packaging materials.
\end{abstract}

Keywords Edible films · Galactomannan · Permeability · Mechanical $\cdot$ Water solubility $\cdot$ Colour

\footnotetext{
M. A. Cerqueira $(\triangle) \cdot$ B. W. S. Souza $\cdot$ J. A. Teixeira

A. A. Vicente

IBB-Institute for Biotechnology and Bioengineering,

Centre of Biological Engineering, University of Minho,

Campus de Gualtar,

4710-057 Braga, Portugal

e-mail: miguelcerqueira@deb.uminho.pt

B. W. S. Souza

Departamento de Engenharia de Pesca,

Universidade Federal do Ceará,

Fortaleza, Ceará, Brazil

\section{Introduction}

The growing importance attributed by consumers and governmental institutions to environmental issues has encouraged food and packaging industries to reduce the amount of synthetic packaging materials used. Concerns with a safer and healthier environment lead to a demand for food of high quality, without chemical preservatives and with an extended shelf-life that increase the efforts to discover, e.g. new packaging materials, natural preservatives and antimicrobials. As an answer to these issues, the commercial use of bio-based primary food packaging materials is being implemented (Chien et al. 2007).

Galactomannans are present in the endosperm of numerous plants, and they have several functions, e.g. as a reserve of carbohydrates. Galactomannans are polysaccharides built up of a $\beta$-(1-4)-D-mannan backbone with single D-galactose branches linked $\alpha-(1-6)$ (Kök et al. 1999). Galactomannans can often be used in different forms for human consumption used for many applications; they are excellent stiffeners and stabilisers of emulsions, and the absence of toxicity allows their use in the textile, pharmaceutical, biomedical, cosmetics and food industries (Srivastava and Kapoor 2005). Gleditsia triacanthos belongs to the family Leguminosae; it grows in America, Middle Europe and Mediterranean area (Üner and Altınkurt 2004). Some works have already used galactomannans from commercial and non-traditional origins as a source for film and coating production (Mikkonen et al. 2007; Cerqueira et al. 2009b, c).

The presence of a plasticizer is often required to improve the mechanical properties of a film or coating. In particular, glycerol is widely used as plasticizer because of its stability and edibility (Bangyekan et al. 2006). Furthermore, in order to improve water barrier 
properties, lipids are frequently incorporated into hydrocolloid-based films (Fabra et al. 2008).

The main objective of this work was to evaluate the effects of galactomannan and plasticizer concentrations and of the presence of oil in water vapour, $\mathrm{O}_{2}$ and $\mathrm{CO}_{2}$ permeabilities, water solubility, tensile strength, elongationat-break, opacity and colour properties.

\section{Materials and Methods}

Film-Forming Solutions and Films Preparation

The film-forming solutions were prepared dissolving the lyophilized galactomannan $(0.5 \%$ or $1.5 \% \mathrm{w} / \mathrm{v})$ in distilled water with agitation using a magnetic stirrer (at $200 \mathrm{rpm}$ ) overnight at room temperature $\left(20{ }^{\circ} \mathrm{C}\right)$. Galactomannan extraction was performed from the seeds of $G$. triacanthos as described by Cerqueira et al. (2009a). Glycerol (87\% of purity, Panreac, Spain) was added in concentrations between $0.5 \%$ and $2.0 \%(w / v)$. Corn oil (Sovena, Portugal) was added in a concentration of $0.5 \%(w / v)$ with agitation for $20 \mathrm{~min}$ at $60^{\circ} \mathrm{C}$. The concentrations were chosen based on preliminary experiments (data not shown) where it was determined that for galactomannan concentrations above $1.5 \%(w / v)$, their dissolution was extremely difficult; also for glycerol, previous studies indicated that for values lower than $0.5 \%(w / v)$, the film would be too brittle. To produce the films, a constant amount $(13 \mathrm{~mL})$ of film-forming solution (at $23{ }^{\circ} \mathrm{C}$ ) was cast onto a $5.7-\mathrm{cm}$ diameter Petri plate. The films were dried in an oven at $35{ }^{\circ} \mathrm{C}$ for $16 \mathrm{~h}$ and maintained at $23{ }^{\circ} \mathrm{C}$ and $53 \% \mathrm{RH}$ before tests; these conditions were obtained through a saturated salt solution of $\mathrm{Mg}\left(\mathrm{NO}_{3}\right)_{2}$.
Film Thickness

The film thickness was measured with a digital micrometer (no. 293-561, Mitutoyo, Japan). Five thickness measurements were taken on each testing sample in different points, and the mean values (see Table 1) were used to calculate permeability and mechanical properties.

\section{Water Vapour Permeability}

The measurement of water vapour permeability $(W V P)$ was performed gravimetrically based on ASTM E96-92 method (McHugh et al. 1993; Guillard et al. 2003) as described by Cerqueira et al. (2011).

The measured WVP of the films was determined as follows:

$\mathrm{WVP}=\left\lfloor\frac{\mathrm{WVTR} \cdot L}{\Delta P}\right\rfloor$

where WVTR is the measured water vapour transmission rate through a film, $L$ is the mean film thickness (in meters) and $\Delta P$ is the partial water vapour pressure difference (in pascal) across the two sides of the film. The measured WVTR of the films was determined as follows:

$\mathrm{WVTR}=\frac{\text { slope }}{\text { film area }}$

where the slope of weight loss versus time was obtained by linear regression and the cup test mouth area was the film area. Three replicates were obtained for each film.

Table 1 Galactomannan, glycerol and oil concentrations used in film formulations (coded levels $-1,0$ and 1 associated to factorial design); values of thickness and water vapour permeability for each film formulation

\begin{tabular}{llllll}
\hline Sample & Galactomannan $(w / v)$ & Glycerol $(w / v)$ & Oil $(w / v)$ & Thickness $(\mathrm{mm})^{\mathrm{a}}$ & $\mathrm{WVP}^{2}\left(10^{11} \mathrm{~g} \mathrm{~ms}^{-1} \mathrm{~Pa}^{-1} \mathrm{~m}^{-2}\right)^{\mathrm{a}}$ \\
\hline 1 & $0.5(-1)$ & $0.5(-1)$ & $0.0(-1)$ & $0.058 \pm 0.004 \mathrm{a}$ & $8.30 \pm 0.33 \mathrm{a}$ \\
2 & $0.5(-1)$ & $2.0(+1)$ & $0.0(-1)$ & $0.060 \pm 0.005 \mathrm{a}$ & $9.24 \pm 0.19 \mathrm{~b}$ \\
3 & $0.5(-1)$ & $0.5(-1)$ & $0.5(+1)$ & $0.059 \pm 0.005 \mathrm{a}$ & $7.70 \pm 0.20 \mathrm{c}$ \\
4 & $0.5(-1)$ & $2.0(+1)$ & $0.5(+1)$ & $0.060 \pm 0.007 \mathrm{a}$ & $8.36 \pm 0.21 \mathrm{a}$ \\
5 & $1.5(+1)$ & $0.5(-1)$ & $0.0(-1)$ & $0.065 \pm 0.005 \mathrm{a}$ & $7.23 \pm 0.14 \mathrm{~d}$ \\
6 & $1.5(+1)$ & $2.0(+1)$ & $0.0(-1)$ & $0.074 \pm 0.005 \mathrm{~b}$ & $9.30 \pm 0.34 \mathrm{~b}$ \\
7 & $1.5(+1)$ & $0.5(-1)$ & $0.5(+1)$ & $0.071 \pm 0.003 \mathrm{~b}$ & $6.11 \pm 0.15 \mathrm{e}$ \\
8 & $1.5(+1)$ & $2.0(+1)$ & $0.5(+1)$ & $0.074 \pm 0.007 \mathrm{~b}$ & $7.11 \pm 0.22 \mathrm{~d}$ \\
\hline
\end{tabular}

Means in the same column with different letters are significantly different $(p<0.05)$

$W V P$ water vapour permeability

${ }^{\text {a }}$ Three replicates were obtained for each sample 
Oxygen, Carbon Dioxide Permeability and $\mathrm{CO}_{2} / \mathrm{O}_{2}$ Permselectivity

Oxygen permeability $\left(\mathrm{O}_{2} P\right)$ and carbon dioxide permeability $\left(\mathrm{CO}_{2} P\right)$ were determined based on the ASTM D 3985-02 (2002) method as described by Cerqueira et al. (2011). Three replicates were obtained for each sample, in each case $\left(\mathrm{O}_{2} \mathrm{P}\right.$ and $\left.\mathrm{CO}_{2} \mathrm{P}\right) \cdot \mathrm{CO}_{2} / \mathrm{O}_{2}$ permselectivity was determined by the ratio between the permeability values of $\mathrm{CO}_{2}$ and $\mathrm{O}_{2}$.

\section{Colour and Opacity}

The colour of the films was determined with a Minolta colorimeter (CR 400; Minolta, Japan). A white standard colour plate $(Y=93.5, x=0.3114, y=0.3190)$ for the instruments' calibration was used as a background for colour measurements of the films, and the $L^{*}, a^{*}, b^{*}$ values of each film were evaluated by reflectance measurements. In this system, $L^{*}$ indicates the lightness (ranging from black to white), and the horizontal axes, indicated by $a^{*}$ and $b^{*}$, are the chromatic coordinates (ranging from $-a^{*}$ : greenness, $b^{*}$ : blueness to $+a^{*}$ : redness, $+b^{*}$ yellowness). The values of $a^{*}$ and $b^{*}$ approach zero for neutral colours and increase as the colour becomes more chromatic and more saturated. The opacity of a material is an indication of how much light passes through it and is calculated from reflectance measurements. The opacity of the samples was determined according to the Hunter lab method, as the relationship between the opacity of each sample on a black standard $\left(Y_{\mathrm{b}}\right)$ and the opacity of each sample on a white standard $\left(Y_{\mathrm{w}}\right)$ (Eq. 3) (Casariego et al. 2009). The measurements were repeated three times for each film.

Opacity $=\frac{Y_{\mathrm{b}}}{Y_{\mathrm{w}}} \cdot 100$

\section{Water Solubility}

The film solubility in water was determined according to the method reported by Cuq et al. (1996). It was defined by the content of dry matter solubilised after $24 \mathrm{~h}$ immersion in water. The initial dry matter content of each film was determined by drying to constant weight in an oven at $105^{\circ} \mathrm{C}$. Two disks of film ( $2 \mathrm{~cm}$ diameter) were cut, weighed $\left(M_{\mathrm{i}}\right)$ and immersed in $50 \mathrm{~mL}$ of water. After $24 \mathrm{~h}$ of immersion at $20{ }^{\circ} \mathrm{C}$ with agitation $(60 \mathrm{rpm})$, the pieces of film were taken out and dried to constant weight $\left(M_{\mathrm{f}}\right)$ in an oven at $105^{\circ} \mathrm{C}$, to determine the weight of dry matter which was not solubilised in water. The measurement of solubility of the films was determined as follows:

$\mathrm{SOL}=\frac{\left(M_{\mathrm{i}}-M_{\mathrm{f}}\right)}{M_{\mathrm{i}}} \cdot 100$ where water solubility $(S O L)$ is the percentage of soluble material, $M_{\mathrm{i}}$ is the initial mass and $M_{\mathrm{f}}$ is the final mass of the sample.

Tensile Strength and Elongation-At-Break

Tensile strength $(T S)$ and elongation-at-break $(E B)$ were measured with an Instron Universal Testing Machine (Model 4500, Instron Corporation) following the guidelines of ASTM Standard Method D 882-91 as described by Cerqueira et al. (2011). TS and EB tests were replicated at least five times (using five different film samples obtained from five different films) for each type of film.

\section{Statistical Analyses}

Data analyses were performed Statistica software (release 7, edition 2004, Statsoft, Tulsa, OK, USA). Table 1 shows the concentrations (levels) used for each variable in the experiments that were applied to the design of two levels, giving a total of eight non-centre-point runs (depending on the property being measured, a different number of replicates was used, as indicated in Tables 1 , 2 and 4). The independent variables were galactomannan, glycerol and oil concentration. Pareto charts were drawn to express visually the statistical significance of each factor and the interactions between factors (Hill and Lewicki 2006). The experimental data were fitted to a multifactor model, represented by Eq. 5:

$$
\begin{aligned}
Y= & a+b \cdot X_{1}+c \cdot X_{2}+d \cdot X_{3}+e \cdot X_{1} \cdot X_{2}+f \cdot X_{1} \\
& \cdot X_{3}+g \cdot X_{2} \cdot X_{3}
\end{aligned}
$$

where $Y$ represents the dependent variables: WVP, $\mathrm{O}_{2} \mathrm{P}$, $\mathrm{CO}_{2} \mathrm{P}$, solubility, TS, EB, opacity, $L^{*}, a^{*}$ or $b^{*}$; being the independent variables: galactomannan $\left(X_{1}\right)$, glycerol $\left(X_{2}\right)$ and oil $\left(X_{3}\right)$. The fitting accuracy of the models was evaluated by the determination of the following parameters: coefficient of determination $\left(R^{2}\right)$, mean relative deviation modulus $(E)$ and accuracy factor $\left(A_{\mathrm{f}}\right) . R^{2}$ provides the percentage of the variance of the data that is explained by the model. The higher the $R^{2}$ value, the better the model fits the experimental data (Neter et al. 1996). The mean relative percentage deviation modulus, $E$, indicates the goodness of the fit between the observed and predicted values of the analysed parameters for the independent variables used, being $N$ the number of data points, $R_{\text {obs }}$ the observed values of each parameter and $R_{\text {pre }}$ the values predicted by the model. Values below $10 \%$ are indicative of a good fit (McLaughlin and O'Beirne 1999). The accuracy factor $\left(A_{\mathrm{f}}\right)$ also provides information on the fitting 
Table 2 Model equations and the corresponding quality of the fit evaluation parameters for: water vapour permeability, oxygen permeability, carbon dioxide permeability, water solubility, tensile strength, elongation-at-break opacity and $L^{*}, a^{*}$ and $b^{*}$ parameters

\begin{tabular}{|c|c|c|c|}
\hline Model equations & $R^{2}$ & $A_{\mathrm{f}}$ & $E$ \\
\hline $\mathrm{WVP}=8.3351-1.1004 * \mathrm{GT}+0.5152 * \mathrm{Gly}+0.7986 * \mathrm{Oil}+0.5510 * \mathrm{GT} * \mathrm{Gly}-2.0158 * \mathrm{GT} *$ Oil $-1.0211 *$ Gly*Oil & 0.96 & 1.02 & 1.50 \\
\hline $\mathrm{O}_{2} \mathrm{P}=1.6885+0.0069 * \mathrm{GT}+0.4858 * \mathrm{Gly}+10.4057 * \mathrm{Oil}+0.3788 * \mathrm{GT} * \mathrm{Gly}-4.2783 * \mathrm{GT} *$ Oil $-8.161 * \mathrm{Gly} *$ Oil & 0.88 & 1.00 & 0.47 \\
\hline $\mathrm{CO}_{2} \mathrm{P}=24.0909-10.1212 * \mathrm{GT}+7.8020 * \mathrm{Gly}+33.6568 * \mathrm{Oil}-0.8353 * \mathrm{GT} * \mathrm{Gly}-17.0416 * \mathrm{GT} * \mathrm{Oil}-8.1609 *$ Gly*Oil & 0.91 & 1.04 & 3.7 \\
\hline $\mathrm{SOL}=58.0986-12.1643 * \mathrm{GT}+4.5037 * \mathrm{Gly}-33.2274 * \mathrm{Oil}+5.0168 * \mathrm{GT} * \mathrm{Gly}+14.9577 * \mathrm{GT} * \mathrm{Oil}-0.5903 *$ Gly*Oil & 0.96 & 1.03 & 3.42 \\
\hline $\begin{array}{l}\mathrm{TS}=-1650.2400+11016.1267 * \mathrm{GT}+577.9200 * \mathrm{Gly}-7682.5200 * \text { Oil }-4150.6933 * \mathrm{GT} * \mathrm{Gly}+3535.6800 * \mathrm{GT} * \text { Oil }+ \\
\quad 3679.6800 * \text { Gly*Oil }\end{array}$ & 0.98 & 1.17 & 15.6 \\
\hline $\mathrm{EB}=55.8686-39.4752 * \mathrm{GT}+12.4769 * \mathrm{Gly}-19.6774 * \mathrm{Oil}+6.2254 * \mathrm{GT} * \mathrm{Gly}+10.3098 * \mathrm{GT} * \mathrm{Oil}+14.1828 *$ Gly*Oil & 0.97 & 1.13 & 13.0 \\
\hline Opacity $=2.9111+6.4675 * \mathrm{GT}-0.5958 * \mathrm{Gly}+5.2227 *$ Oil $-1.5973 * \mathrm{GT} * \mathrm{Gly}-0.3572 * \mathrm{GT} *$ Oil $-1.8354 *$ Gly $*$ Oil & 0.92 & 1.04 & 3.46 \\
\hline$L^{*}=92.4495-6.2921 * \mathrm{GT}-0.0185 * \mathrm{Gly}+1.1915 *$ Oil $-0.2130 * \mathrm{GT} * \mathrm{Gly}-1.8567 * \mathrm{GT} *$ Oil $-0.1652 * \mathrm{Gly} *$ Oil & 0.83 & 1.01 & 0.77 \\
\hline$a^{*}=5.2582+0.8356 * \mathrm{GT}-0.3390 * \mathrm{Gly}-0.1758 * \mathrm{Oil}+0.3679 * \mathrm{GT} * \mathrm{Gly}+0.1349 * \mathrm{GT} * \mathrm{Oil}-0.0247 * \mathrm{Gly} * \mathrm{Oil}$ & 0.76 & 1.16 & 13.2 \\
\hline$b^{*}=8.0621+9.7799 * \mathrm{GT}+0.7119 * \mathrm{Gly}-6.5315 * \mathrm{O} i 1-1.2137 * \mathrm{GT} * \mathrm{Gly}+1.1544 * \mathrm{GT} * \mathrm{O} 1+2.1119 * \mathrm{Gly} * \mathrm{O}$ il & 0.81 & 1.10 & 9.8 \\
\hline
\end{tabular}

WVP water vapour permeability, $\mathrm{O}_{2} \mathrm{P}$ oxygen permeability, $\mathrm{CO}_{2} \mathrm{P}$ carbon dioxide permeability, $\mathrm{SOL}$ water solubility, $T S$ tensile strength, $E B$ elongation-at-break, $L^{*} a^{*} b^{*}$ opacity parameters

accuracy. The closer the $A_{\mathrm{f}}$ value is to 1 , the better the accuracy (Ross 1996).

\section{Results and Discussion}

\section{Water Vapour Permeability}

In Fig. 1a, the Pareto charts showed that galactomannan concentration (-9.88), glycerol (13.13) and oil $(-13.45)$ presence are the most significant factors $(p<0.05)$ influencing the values of WVP. Oil presents the highest value, in Pareto charts, presenting a negative effect, where the increase of oil leads to lower values of WVP. The presence of the hydrophobic oil blended with galactomannan changes film properties decreasing their water affinity, decreasing the WVP values for samples with the same concentrations of galactomannan and glycerol (Table 1). This behaviour has been justified by the reduction of the hydrophilic portion of the film (Hernandez-Munõz et al. 2004). Also, the interactions between galactomannan and glycerol (4.46), between glycerol and oil (-4.13) and galactomannan and oil (-5.44) seem to be influent factors $(p<0.05)$. The interaction with the greatest significance was the interaction between galactomannan and oil, where the increase of galactomannan concentration and the presence of oil lead to lower values of WVP. The glycerol and the interaction between galactomannan and glycerol have a positive correlation, which can be explained by the hygroscopic character of glycerol that tends to draw additional water into the matrix turning it more hydrophilic. Oppositely, the interaction between oil and glycerol shows a negative correlation, being the hygroscopic character of glycerol counterbalanced by the hydrophobic character of the oil.
Also, glycerol concentration is a significant factor $(p<$ 0.05 ) affecting WVP values (Fig. 1a). Higher concentrations of plasticizer favour the adsorption of water molecules, which is mainly attributed to the predisposition of plasticizers to form hydrogen bonds, increasing WVP values (Diab et al. 2001). In fact, plasticizers and their plasticizing action change the polymer network creating mobile regions with greater interchain distances, promoting water clustering by competing with water at active sites of the polymer matrix (Olivas and Barbosa-Cánovas 2008). For all the studied samples and when the galactomannan and oil concentrations are kept constant, the increase of glycerol concentration leads to higher WVP values (Table 1). Also by Cerqueira et al. (2011), the oil presence and glycerol concentrations are two most influent factors in the WVP values for polysaccharide films.

The increase of galactomannan concentrations results in the increase of film thickness (with exception of sample 5) (Table 1), thus influencing the resistance to water movement through the film (McHugh et al. 1993; Aydinli and Tutas 2000).

The obtained values are in agreement with those obtained in other works (Cerqueira et al. 2009b, c; Aydinli and Tutas 2000). Galactomannan films showed WVP values in the range of cellophane films (1 to $11 \times 10^{-11} \mathrm{~g} \mathrm{~mm}^{-1} \mathrm{~s}^{-1} \mathrm{~Pa}^{-1}$ ) (Han and Gennadios 2005). When the model equation (Eq. 5) was fitted to WVP experimental data, a good fit was obtained in all cases, with values of $R^{2}$ above $0.96, E$ below $10 \%$ and $A_{\mathrm{f}}$ very close to 1 (Table 2 ).

Oxygen $\left(\mathrm{O}_{2} \mathrm{P}\right)$, Carbon Dioxide Permeability and $\mathrm{CO}_{2} / \mathrm{O}_{2}$ Permselectivity

The results showed that $\mathrm{O}_{2} \mathrm{P}$ and $\mathrm{CO}_{2} \mathrm{P}$ values in galactomannan films are very sensitive to the addition and/or 
increasing concentrations of polysaccharide, plasticizer and oil (Fig. 1b, c). Figure 1b, c shows that the interaction between galactomannan and glycerol is the only one that does not statistically influence $(p>0.05)$ the values of $\mathrm{O}_{2} \mathrm{P}$ and $\mathrm{CO}_{2} \mathrm{P}$. On the contrary, oil and polysaccharide concentrations are the most significant factors affecting $\mathrm{O}_{2} \mathrm{P}$ and $\mathrm{CO}_{2} \mathrm{P}$, respectively. For $\mathrm{O}_{2} \mathrm{P}$, the oil presence is the most influent factor (12.82) that leads to the increasing of $\mathrm{O}_{2} \mathrm{P}$

(a)

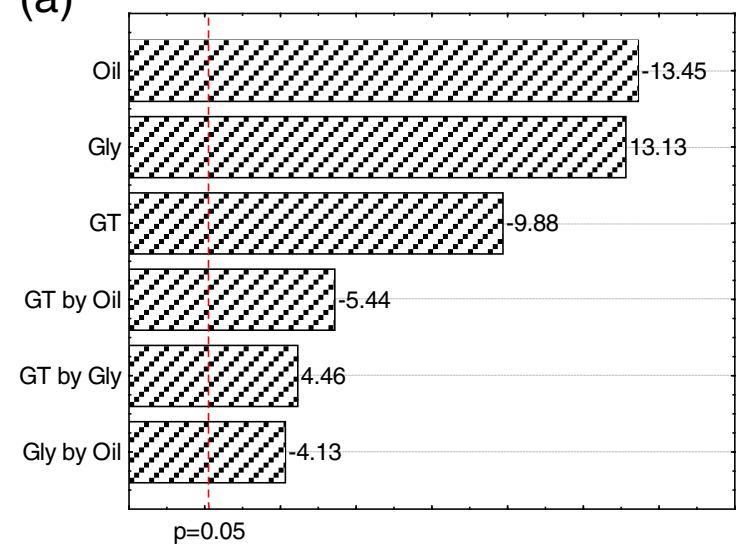

(c)

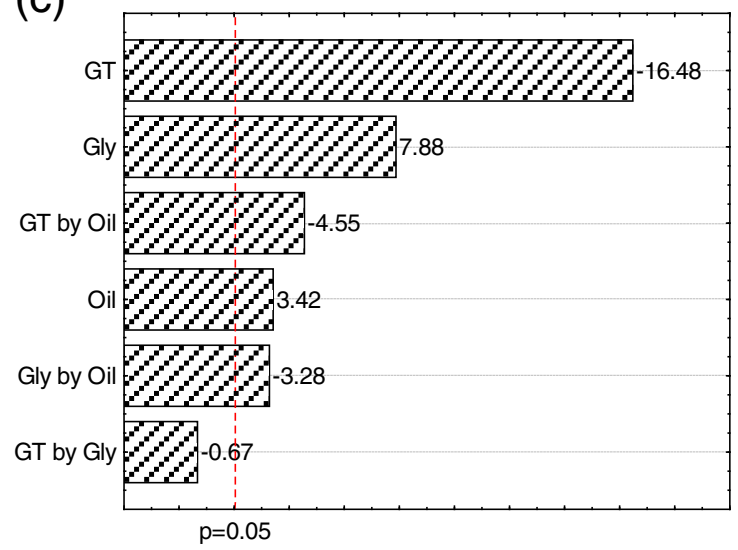

(e)

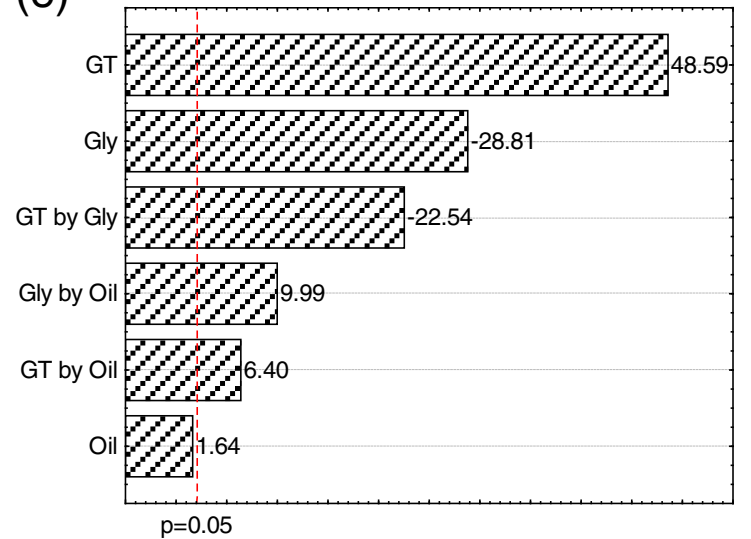

values of the films. For films with $0.5 \%$ of galactomannan, the oil presence increases $\mathrm{O}_{2} \mathrm{P}$ and $\mathrm{CO}_{2} \mathrm{P}$ values in $10 \%$ and $20 \%$, respectively (Table 3 ). The higher values of $\mathrm{O}_{2} \mathrm{P}$ and $\mathrm{CO}_{2} \mathrm{P}$ obtained for films containing oil when compared to similar concentrations of galactomannan and glycerol can be explained by the presence of oil droplets inserted between galactomannan chains, which interrupt the film matrix and possibly contribute to develop a more open structure. The

(b)

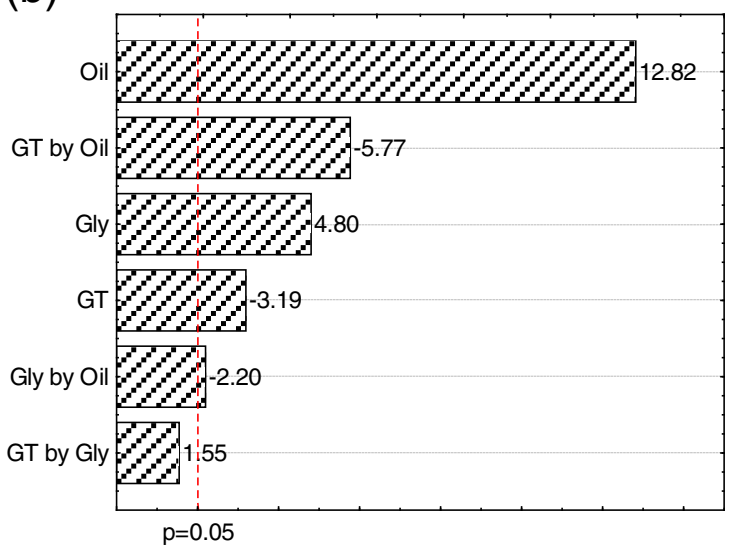

(d)

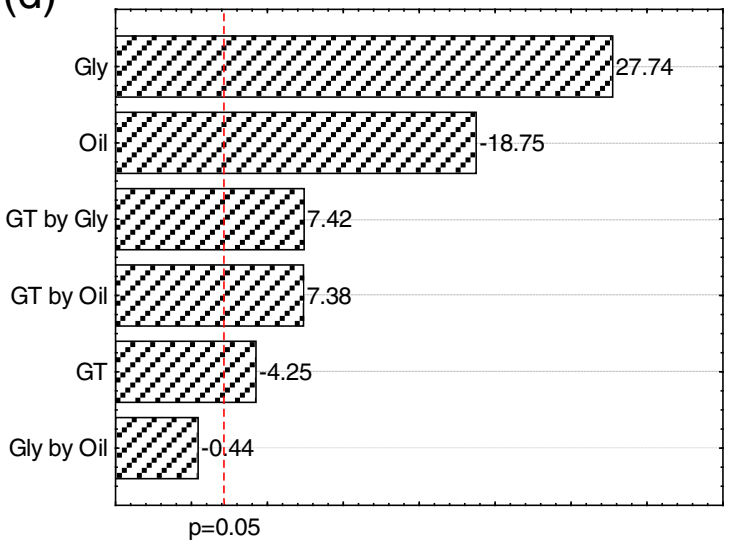

(f)

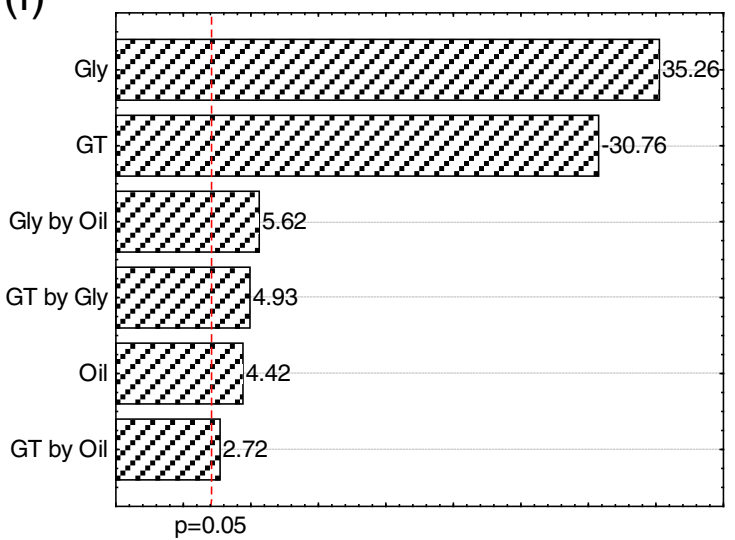

Fig. 1 Pareto charts of the effects for water vapour permeability (a), oxygen permeability (b), carbon dioxide permeability (c), solubility (d), tensile strength (e), elongation-at-break (f), opacity $(\mathbf{g})$ and colour coordinates $L^{*}(\mathbf{h}), a^{*}(\mathbf{i})$ and $b^{*}(\mathbf{j})$ 
(g)

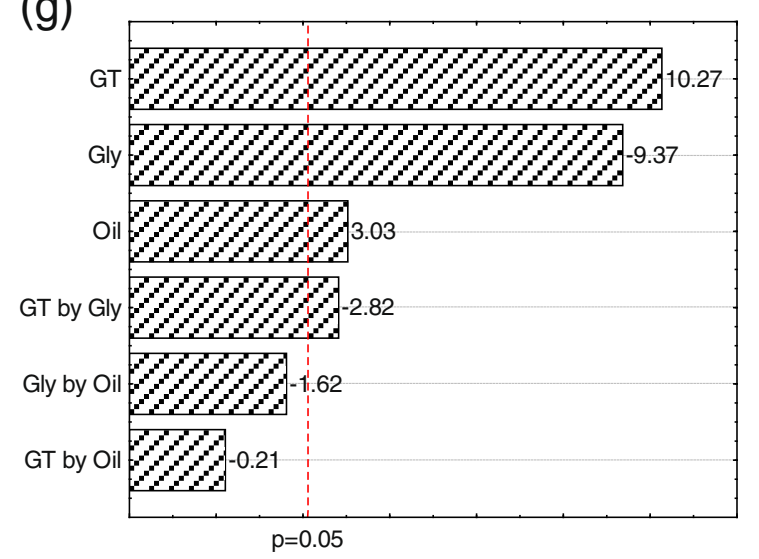

(i)

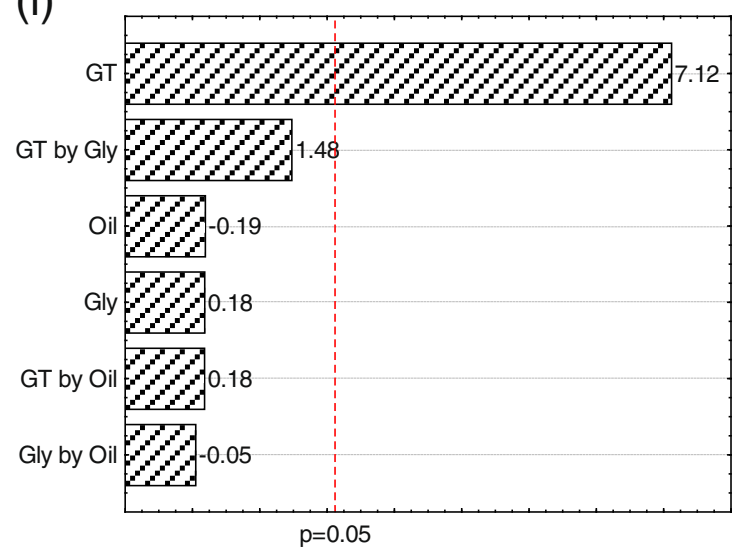

(h)

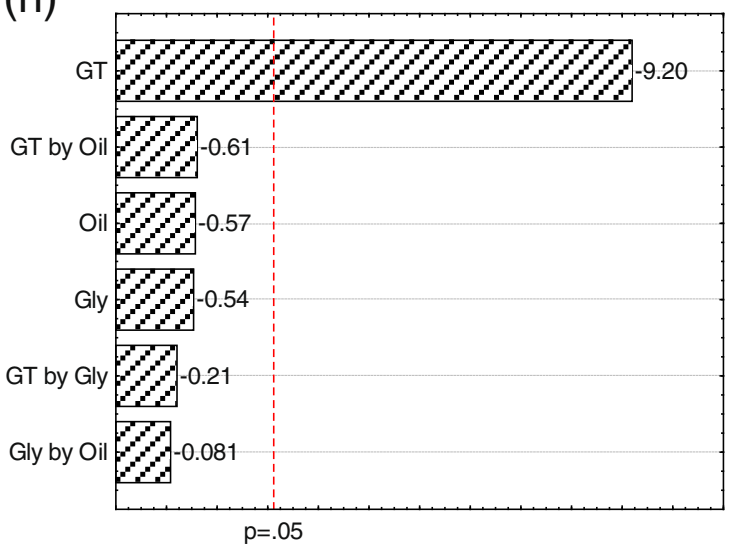

(j)

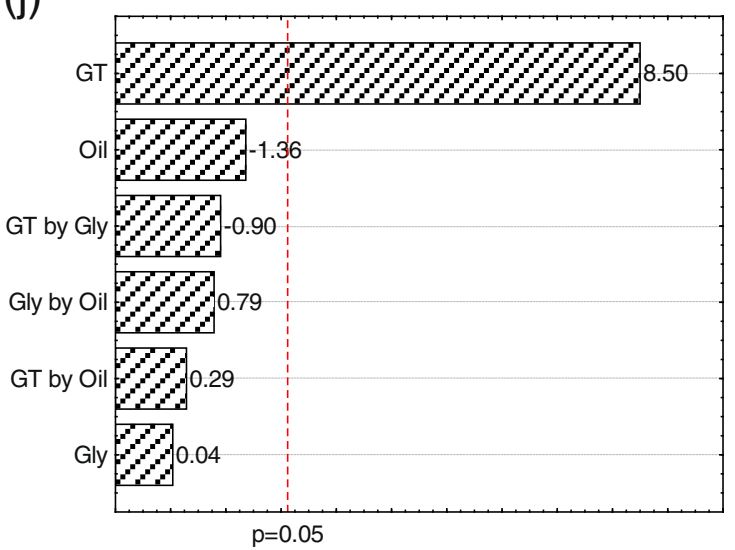

Fig. 1 (continued)

interaction between galactomannan concentration and the oil presence presents in both cases $\left(\mathrm{O}_{2} \mathrm{P}\right.$ and $\left.\mathrm{CO}_{2} \mathrm{P}\right)$ a negative correlation leading to lower permeability values. Higher glycerol concentrations provoke an increase of both
$\mathrm{O}_{2} \mathrm{P}$ and $\mathrm{CO}_{2} \mathrm{P}$ values (Table 3 ). The addition of plasticizer increases the free volume of the film leading to an increase of permeability values (Miller and Krochta 1997). Moreover, the hydrophilicity of the glycerol molecule, which

Table 3 Values of oxygen permeability, carbon dioxide permeability, $\mathrm{CO}_{2} / \mathrm{O}_{2}$ permselectivity, water solubility, tensile strength and elongation-atbreak for each film's formulation

\begin{tabular}{|c|c|c|c|c|c|c|}
\hline Sample & $\begin{array}{l}\mathrm{O}_{2} \mathrm{P}^{\mathrm{a}} \\
\left(\times 10^{-15} \mathrm{~g} \mathrm{mPa}^{-1} \mathrm{~s}^{-1} \mathrm{~m}^{-2}\right)\end{array}$ & $\begin{array}{l}\mathrm{CO}_{2} \mathrm{P}^{\mathrm{a}} \\
\left(\times 10^{-15} \mathrm{~g} \mathrm{mPa}^{-1} \mathrm{~s}^{-1} \mathrm{~m}^{-2}\right)\end{array}$ & $\begin{array}{l}\mathrm{CO}_{2} \mathrm{P} / \mathrm{O}_{2} P \\
\text { permselectivity }\end{array}$ & $\operatorname{SOL}(\%)^{\mathrm{a}}$ & $\mathrm{TS}(\mathrm{kPa})^{\mathrm{b}}$ & $\mathrm{EB}(\%)^{\mathrm{b}}$ \\
\hline 1 & $2.04 \pm 0.81 \mathrm{a}$ & $23.37 \pm 4.62 \mathrm{af}$ & 11.46 & $57.80 \pm 0.26 \mathrm{a}$ & $2735.0 \pm 213.5 \mathrm{a}$ & $41.17 \pm 2.48 \mathrm{a}$ \\
\hline 2 & $3.02 \pm 0.59 \mathrm{ac}$ & $33.15 \pm 2.23 b$ & 10.98 & $63.77 \pm 2.10 \mathrm{~b}$ & $1237.1 \pm 202.9 b$ & $70.07 \pm 3.99 b$ \\
\hline 3 & $5.87 \pm 0.57 \mathrm{~b}$ & $32.48 \pm 2.25 b$ & 5.53 & $40.99 \pm 0.73 c$ & $1445.8 \pm 190.3 b$ & $42.97 \pm 3.87 \mathrm{a}$ \\
\hline 4 & $6.10 \pm 0.77 b$ & $38.76 \pm 1.65 \mathrm{c}$ & 6.35 & $54.85 \pm 0.99 \mathrm{~d}$ & $1211.2 \pm 128.8 b$ & $71.47 \pm 2.34 b$ \\
\hline 5 & $2.22 \pm 0.72 \mathrm{a}$ & $11.41 \pm 1.12 \mathrm{~d}$ & 5.14 & $44.35 \pm 0.47 \mathrm{e}$ & $12424.0 \pm 646.7 \mathrm{c}$ & $10.32 \pm 2.25 \mathrm{c}$ \\
\hline 6 & $3.82 \pm 0.20 \mathrm{c}$ & $22.78 \pm 1.44 \mathrm{af}$ & 5.96 & $65.43 \pm 1.53 b$ & $3203.6 \pm 579.0 \mathrm{a}$ & $37.53 \pm 3.74 a$ \\
\hline 7 & $3.97 \pm 0.24 \mathrm{c}$ & $15.16 \pm 2.54 \mathrm{e}$ & 3.82 & $41.84 \pm 1.11 \mathrm{f}$ & $11406.2 \pm 600.1 \mathrm{c}$ & $6.25 \pm 1.93 c$ \\
\hline 8 & $4.89 \pm 0.28 \mathrm{~d}$ & $17.12 \pm 3.96 \mathrm{fe}$ & 3.50 & $56.41 \pm 1.17 \mathrm{ad}$ & $6442.0 \pm 522.7 \mathrm{~d}$ & $55.12 \pm 2.52 \mathrm{~d}$ \\
\hline
\end{tabular}

Means in the same column with different letters are significantly different $(p<0.05)$

$\mathrm{O}_{2} \mathrm{P}$ oxygen permeability, $\mathrm{CO}_{2} \mathrm{P}$ carbon dioxide permeability, $\mathrm{SOL}$ water solubility, $T S$ tensile strength, $E B$ elongation-at-break

${ }^{a}$ Three replicates were obtained for each sample

${ }^{\mathrm{b}}$ Five replicates were obtained for each sample 
favours the adsorption of water molecules, might enhance the solubility of the gases in the films, increasing their permeability. On the other side, the increase of galactomannan concentration while maintaining glycerol and oil concentration leads to a decrease of $\mathrm{O}_{2} \mathrm{P}$ values (in some cases) and of $\mathrm{CO}_{2} \mathrm{P}$ values (in all cases). The values obtained for $\mathrm{CO}_{2} \mathrm{P}$ were systematically higher when compared with those of $\mathrm{O}_{2} \mathrm{P}$, which is generally attributed to the solubility of these gases in water. $\mathrm{CO}_{2}$ is approximately 35 times more soluble than $\mathrm{O}_{2}$, and this is the reason why this gas diffuses much faster, therefore increasing its permeability (Mujica-Paz and Gontard 1997). The galactomannan films evaluated in this work presented oxygen permeability values in the range of, e.g. high-density polyethylene films (Han and Gennadios 2005).

The ratio between $\mathrm{CO}_{2}$ and $\mathrm{O}_{2}$ permeabilities, defined as $\mathrm{CO}_{2} / \mathrm{O}_{2}$ permselectivity, were also calculated due their implication in designing packaging films for food applications (Park and Chinnan 1995; Al-Ati and Hotchkiss 2003; Wu et al. 2009). Commercial packaging films have $\mathrm{CO}_{2} / \mathrm{O}_{2}$ permselectivities ranged between 4 and 8 (Al-Ati and Hotchkiss 2003). A higher ratio indicates a less accumulation of $\mathrm{CO}_{2}$ and vice versa that can be important for the application as packaging in food industry. The $\mathrm{CO}_{2} / \mathrm{O}_{2}$ permselectivity of galactomannan films presents value range between 3.50 and 11.46. This range of $\mathrm{CO}_{2} / \mathrm{O}_{2}$ permselectivity values allows the use of different film formulations to obtain the desired modified atmosphere in fruits and vegetables (e.g. lettuce, carrots and apples) (Exama et al. 1993). When fitted to $\mathrm{O}_{2} \mathrm{P}$ and $\mathrm{CO}_{2} \mathrm{P}$ data (Table 2), the model equation (Eq. 5) presents an acceptable value for $R^{2}$ (above 0.88 ), values of $A_{\mathrm{f}}$ close to 1 and $E$ below $10 \%$.

\section{Water Solubility}

Figure $1 \mathrm{~d}$ indicates that only the interaction between glycerol and oil does not influence the water solubility values for the tested films. The presence of oil and the increase of the glycerol concentration show different behaviours. The increase of the glycerol concentration leads to an increase of the solubility (Table 3 ), being the most influent factor (27.74) affecting the solubility values. This is possibly due to the increase of the hydrophilicity with the increase of glycerol concentration. These results are in agreement with the behaviour observed for WVP results. Oil addition promotes the decrease of film solubility due to its hydrophobic character (Table 3). The interaction between galactomannan and glycerol and galactomannan and oil presents similar behaviours (Fig. 1d), with the increasing of solubility values.

These results are in agreement with the solubility values obtained by other authors (Casariego et al. 2009; Piermaria et al. 2009; Mehyar and Han 2004). The fitting of the model equation (Eq. 5) to the experimental values of SOL shows good results, with values of $R^{2}$ above $0.96, E$ below $10 \%$ and $A_{\mathrm{f}}$ very close to 1 (Table 2 ).

\section{Tensile Strength}

All studied factors in this work have a significant $(p<0.05)$ influence on TS with exception of the oil (Fig. 1e). The increase of galactomannan concentration (while keeping the other factors constant) increased TS values (Fig. 1e). The increase of galactomannan concentration leads to a stronger gel network, where the polysaccharide molecules are closer, forming a more coherent film structure, and reducing the absorption of water molecules. Of course, TS values are also affected by other factors (Fig. 1e). The increase of plasticizer concentration had great influence (Fig. 1e) on the values of TS for films of $1.5 \%$ of galactomannan (Table 3); the plasticizing effect of glycerol, which acts by changing the polymer network and creating more mobile regions with larger interchain distances, is possibly the main reason for its influence on TS. The same behaviour was reported for chitosan films, where chitosan and plasticizer (glycerol) concentrations were the factors with most influence on TS values (Cerqueira et al. 2011). Also, the interaction between galactomannan and glycerol presents a great effect in the TS of the films (Fig. 1e), leading to a decrease of the TS values.
Table 4 Values of opacity and colour parameters for each film's formulation

Means in the same column with different letters are significantly different $(p<0.05)$

${ }^{\mathrm{a}}$ Three replicates were obtained for each sample

\begin{tabular}{lllll}
\hline Sample & Opacity $^{\mathrm{a}}$ & $L^{* \mathrm{a}}$ & $a^{* \mathrm{a}}$ & $b^{* \mathrm{a}}$ \\
\hline 1 & $5.23 \pm 0.20 \mathrm{a}$ & $89.69 \pm 3.18 \mathrm{a}$ & $5.51 \pm 0.64 \mathrm{a}$ & $12.31 \pm 4.75 \mathrm{ab}$ \\
2 & $3.56 \pm 0.21 \mathrm{~b}$ & $88.60 \pm 0.49 \mathrm{a}$ & $5.45 \pm 0.05 \mathrm{a}$ & $13.86 \pm 0.72 \mathrm{a}$ \\
3 & $7.72 \pm 0.11 \mathrm{c}$ & $88.88 \pm 0.46 \mathrm{a}$ & $5.62 \pm 0.11 \mathrm{a}$ & $11.25 \pm 1.35 \mathrm{~b}$ \\
4 & $3.83 \pm 0.21 \mathrm{~b}$ & $89.47 \pm 0.43 \mathrm{a}$ & $5.20 \pm 0.07 \mathrm{a}$ & $11.60 \pm 0.61 \mathrm{~b}$ \\
5 & $11.30 \pm 1.33 \mathrm{~d}$ & $82.39 \pm 0.97 \mathrm{~b}$ & $6.70 \pm 0.47 \mathrm{~b}$ & $22.87 \pm 1.23 \mathrm{c}$ \\
6 & $6.10 \pm 0.09 \mathrm{e}$ & $82.79 \pm 2.77 \mathrm{~b}$ & $6.85 \pm 0.67 \mathrm{~b}$ & $19.82 \pm 3.18 \mathrm{c}$ \\
7 & $12.77 \pm 2.62 \mathrm{~d}$ & $82.46 \pm 0.56 \mathrm{~b}$ & $6.54 \pm 0.52 \mathrm{~b}$ & $19.61 \pm 1.83 \mathrm{c}$ \\
8 & $7.33 \pm 0.64 \mathrm{c}$ & $80.92 \pm 2.88 \mathrm{~b}$ & $7.01 \pm 0.55 \mathrm{~b}$ & $20.92 \pm 2.89 \mathrm{c}$ \\
\hline
\end{tabular}


Results show in some cases (samples 5 and 7) that tensile strength values close to those reported for high-density polyethylene and low-density polyethylene (ranged between 10 and $100 \mathrm{MPa}$ ) (Han and Gennadios 2005). The fitting of the model equation (Eq. 4) to the experimental values of TS shows a good value of $R^{2}$, above 0.98 (Table 2).

\section{Elongation-At-Break}

All studied factors in this work have significant $(p<0.05)$ effects on EB (Fig. 1f). The most significant factors were the plasticizer concentration (the increase of the plasticizer concentration leads to an increase of EB) and the galactomannan concentration (the increase of galactomannan concentration provokes a decrease of EB) (Table 3). Plasticizers interfere with galactomannan chains where, by decreasing intermolecular forces, they reduce the rigidity of the film structure and increase the polymer mobility, thus facilitating film elongation. These results are in agreement with other works where different sources of galactomannans were used (Mikkonen et al. 2007; Cerqueira et al. 2009b). Similar results are presented for chitosan films (Cerqueira et al. 2011) where all the analysed factors influenced EB values to some extent.

In the present work, EB values ranged between $6.25 \pm$ $1.93 \%$ and $71.47 \pm 2.34 \%$. The highest value of $E B$ was obtained for the film formulation containing $0.5 \%$ of galactomannan, $2.0 \%$ of glycerol and $0.5 \%$ of oil. The fitting of the model equation (Eq. 4) to the experimental values of EB shows values of $R^{2}$ above $0.97, E$ below $20 \%$ and $A_{\mathrm{f}}$ of 1.30 (Table 2).

\section{Opacity and Colour Parameters}

Galactomannan concentration is the most important factor $(p<0.05)$ affecting the opacity of films, followed by the interaction between galactomannan and plasticizer concentration and by the presence of oil (Fig. 1g). The increase of galactomannan concentration originates a film matrix with a stronger polymer network, this factor possibly explaining the higher values of opacity obtained; on the other hand, the increase of glycerol concentration leads to an increase of the free volume of the polymer network, as explained elsewhere (Miller and Krochta 1997), thus increasing the mobility of the polymer chains and possible decreasing the opacity by permitting a better penetration of light. Also by Cerqueira et al. (2011), the increase of chitosan concentrations led to higher opacity values, being the chitosan concentration the most influent factor in the opacity of chitosan films. The presence of oil increases film opacity; such increase is more pronounced for films with $0.5 \%$ of glycerol (Table 4 ). The increase of opacity registered when oil was added was probably a result from the presence of oil droplets that formed during coating formulation and that are dispersed in the emulsion and distributed throughout the polymer matrix after the film is formed. The colour of the film is an important factor in terms of consumer acceptance. In the $L^{*} a^{*} b^{*}$ colour system, galactomannan concentration was the only factor that was shown to have a statistically influence on $L^{*}, a^{*}$ and $b^{*}$ colour parameters (subpanels $\mathrm{h}, \mathrm{i}$ and $\mathrm{j}$ of Fig. 1, respectively). Table 4 shows the obtained values for the $L^{*}, a^{*}$ and $b^{*}$ parameters of the films. The increase of galactomannan concentration decreases $L^{*}$ (lightness). The increase of galactomannan concentration also leads to an increase of $b^{*}$ meaning that the films will become more yellowish. The fitting of the model equation (Eq. 5) to the experimental values of opacity, $L^{*}$ and $b^{*}$ shows good results, with values of $R^{2}$ above $0.81, E$ below $10 \%$ and an $A_{\mathrm{f}}$ value close to 1.00 (Table 2).

\section{Conclusion}

This work provides an insight on how different galactomannan-based films formulations can change film properties. Galactomannan concentration was the most significant factor affecting film properties. Oil incorporation has shown to be of a great importance to the permeability and solubility properties, essentially due to its hydrophobicity. The galactomannan films evaluated in this work provide a good oxygen barrier (in the range of, e.g. high-density polyethylene films) have water vapour permeability and elongation-at-break values in the range of, e.g. cellophane films; they also show in some cases tensile strength values close to those reported for high-density polyethylene and low-density polyethylene. These results provide important information on the use of galactomannan films as an alternative to non-biodegradable, non-edible materials.

Acknowledgements The author M.A. Cerqueira is recipient of a fellowship from Fundação para a Ciência e Tecnologia (FCT, SFRH/ $\mathrm{BPD} / 72753 / 2010$ ) and B.W.S. Souza is a recipient of a fellowship from the Coordenação de Aperfeiçoamento de Pessoal de Nível Superior, Brazil (Capes, Brazil).

\section{References}

Al-Ati, T., \& Hotchkiss, J. H. (2003). The role of packaging film permselectivity in modified atmosphere packaging. Journal of Agricultural and Food Chemistry, 2003(51), 4133-4138.

ASTM D 3985-02. (2002). Standard test method for oxygen gas transmission rate through plastic film and sheeting using a coulometric sensor. In: Annual book of ASTM. Philadelphia, PA: American Society for Testing \& Materials.

Aydinli, M., \& Tutas, M. (2000). Water sorption and water vapour permeability properties of polysaccharide (locust bean gum) based edible films. LWT-Food Science and Technology, 33(1), 63-67. 
Bangyekan, C., Aht-Ong, D., \& Srikulkit, K. (2006). Preparation and properties evaluation of chitosan-coated cassava starch films. Carbohydrate Polymers, 63, 61-71.

Casariego, A., Souza, B. W. S., Cerqueira, M. A., Teixeira, J. A., Cruz, L., Díaz, R., et al. (2009). Chitosan/clay films' properties as affected by biopolymer and clay micro/nanoparticles concentrations. Food Hydrocolloids, 23(7), 1895-1902.

Cerqueira, M. A., Pinheiro, A. C., Souza, B. W. S., Lima, A. M. P., Teixeira, J. A., Moreira, R. A., et al. (2009a). Extraction, purification and characterization of galactomannans from nontraditional sources. Carbohydrate Polymers, 75(3), 408-414.

Cerqueira, M. A., Lima, A. M. P., Teixeira, J. A., Moreira, R. A., \& Vicente, A. A. (2009b). Suitability of novel galactomannans as edible coatings for tropical fruits. Journal of Food Engineering, 94(3-4), 372-378.

Cerqueira, M. A., Lima, A. M., Souza, B. W. S., Teixeira, J. A., Moreira, R. A., \& Vicente, A. A. (2009c). Functional polysaccharides as edible coatings for cheese. Journal of Agricultural and Food Chemistry, 57(4), 1456-1462.

Cerqueira, M. A., Souza, B. W. S., Teixeira, J. A., \& Vicente, A. A. (2011). Effects of interactions between the constituents of chitosan-edible films on their physical properties. Food and Bioprocess Technology: An International Journal. doi:10.1007/ s11947-011-0663-y.

Chien, P., Sheu, F., \& Yang, F. (2007). Effects of edible chitosan coating on quality and shelf life of sliced mango fruit. Journal of Food Engineering, 78, 225-229.

Cuq, B., Gontard, N., Cuq, J. L., \& Guilber, S. (1996). Functional properties of myofibrillar protein based biopackaging as affected by film thickness. Journal of Food Science, 61(3), 580-584.

Diab, T., Biliaderis, C. G., Gerasopoulos, D., \& Sfakiotakis, E. (2001). Physicochemical properties and application of pullunan edible films and coatings in fruit preservation. Journal of the Science of Food and Agriculture, 81, 988-1000.

Exama, A., Arul, J., Lencki, R. W., Lee, L. Z., \& Toupin, C. (1993). Suitability of plastic films for modified atmosphere packaging of fruits and vegetables. Journal of Food Science, 58, 13651370 .

Fabra, M. J., Talens, P., \& Chiralt, A. (2008). Effect of alginate and $\lambda$ carrageenan on tensile properties and water vapour permeability of sodium caseinate-lipid based films. Carbohydrate Polymers, 74(3), 419-426.

Guillard, V., Broyart, B., Bonazzi, C., Guilbert, S., \& Gontard, N. (2003). Preventing moisture transfer in a composite food using edible films: Experimental and mathematical study. Journal of Food Science, 68(7), 2267-2277.

Han, J.H., \& Gennadios, A. (2005). Edible films and coatings: a review. In Han, J., Innovations in Food Packaging (pp. 239259). Elsevier Science \& Technology Books.

Hernandez-Munõz, P., López-Rubio, A., Del-Valle, V., Almenar, E., \& Gavara, R. (2004). Mechanical and water barrier properties of glutenin films influenced by storage time. Journal of Agricultural and Food Chemistry, 52, 79-83.
Hill, T., \& Lewicki, P. (2006). Statistics: Methods and applications (1st ed.). Tulsa: StatSoft.

Kök, M. S., Hill, S. E., \& Mitchell, J. R. (1999). Viscosity of galactomannans during high temperature processing: Influence of degradation and solubilisation. Food Hydrocolloids, 13, 535-542.

McHugh, T. H., Avena-Bustillos, R. J., \& Krochta, J. M. (1993). Hydrophilic edible film: Modified procedure for water vapor permeability and explanation of thickness effects. Journal of Food Science, 58, 899-903.

McLaughlin, C. P., \& O’Beirne, D. (1999). Respiration rate of a dry coleslaw mix as affected by storage temperature and respiratory gas concentrations. Journal of Food Science, 64(1), 116-119.

Mehyar, G. F., \& Han, J. H. (2004). Physical and mechanical properties of high-amylose rice and pea starch films as affected by relative humidity and plasticizer. Journal of Food Science, 69(9), E449E454.

Mikkonen, K. S., Rita, H., Helén, H., Talja, R. A., Hyvönen, L., \& Tenkanen, M. (2007). Effect of polysaccharide structure on mechanical and thermal properties of galactomannan-based films. Biomacromolecules, 8, 3198-3205.

Miller, K. S., \& Krochta, J. M. (1997). Oxygen and aroma barrier properties of edible films: A review. Trends Food ScienceTechnology, 81, 228-237.

Mujica-Paz, H., \& Gontard, N. (1997). Oxygen and carbon dioxide permeability of wheat gluten film: Effect of relative humidity and temperature. Journal of Agriculture and Food Chemistry, 45(10), 4101-4105.

Neter, J., Kutner, M. H., Nachtsheim, C. J., \& Wasserman, W. (1996). Applied linear regression models (pp. 78-85). Chicago: McGraw-Hill.

Olivas, G. I., \& Barbosa-Cánovas, G. V. (2008). Alginate-calcium films: Water vapor permeability and mechanical properties as affected by plasticizer and relative humidity. LWT-Food Science and Technology, 41, 359-366.

Park, H. J., \& Chinnan, M. S. (1995). Gas and water vapor barrier properties of edible films from protein and cellulosic materials. Journal of Food Engineering, 25, 497-507.

Piermaria, J. A., Pinotti, A., Garcia, M. A., \& Abraham, A. G. (2009). Films based on kefiran, an exopolysaccharide obtained from kefir grain: Development and characterization. Food Hydrocolloids, $23,684-690$.

Ross, T. (1996). Indices for performance evaluation of predictive models in food microbiology. Journal of Applied Bacteriology, 81(5), 501-508.

Srivastava, M., \& Kapoor, V. P. (2005). Seed galactomannans: An overview. Chemistry \& Biodiversity, 2, 295-317.

Üner, M., \& Altınkurt, T. (2004). Evaluation of honey locust (Gleditsia triacanthos Linn.) gum as sustaining material in tablet dosage forms. Il Farmaco, 59, 567-573.

Wu, R.-L., Wang, X.-L., Wang, Y.-Z., Bian, X.-C., \& Li, F. (2009). Cellulose/soy protein isolate blend films prepared via roomtemperature ionic liquid. Industrial and Engineering Chemistry Research, 48(15), 7132-7136. 